\title{
(C) OPEN ACCESS \\ Secular trend, seasonality and effects of a community-based intervention on neonatal mortality: follow-up of a cluster-randomised trial in Quang Ninh province, Vietnam
}

\author{
Leif Eriksson, ${ }^{1,2}$ Nguyen T Nga, ${ }^{3}$ Dinh T Phuong Hoa, ${ }^{4}$ Duong M Duc, ${ }^{4}$ \\ Anna Bergström, ${ }^{2,5}$ Lars Wallin, 6,7,8 Mats Målqvist, ${ }^{2}$ Uwe Ewald, ${ }^{2}$ Tran Q Huy, ${ }^{9}$ \\ Nguyen T Thuy, ${ }^{10}$ Tran Thanh Do, ${ }^{11}$ Pham T L Lien, ${ }^{3}$ Lars-Åke Persson, ${ }^{2,12}$ \\ Katarina Ekholm Selling ${ }^{2}$
}

For numbered affiliations see end of article.

\section{Correspondence to} Dr Leif Eriksson, Department of Public Health and Caring Sciences, Uppsala University, Uppsala 751 85, Sweden; leif. eriksson@pubcare.uu.se

Received 26 March 2017 Revised 3 April 2018 Accepted 28 April 2018 Published Online First 15 May 2018
Check for updates

To cite: Eriksson L, Nga NT, Hoa DTP, et al. J Epidemiol Community Health 2018:72:776-782.

\section{ABSTRACT}

Background Little is know about whether the effects of community engagement interventions for child survival in low-income and middle-income settings are sustained. Seasonal variation and secular trend may blur the data. Neonatal mortality was reduced in a cluster-randomised trial in Vietnam where laywomen facilitated groups composed of local stakeholders employing a problemsolving approach for 3 years. In this analysis, we aim at disentangling the secular trend, the seasonal variation and the effect of the intervention on neonatal mortality during and after the trial.

Methods In Quang Ninh province, 44 communes were allocated to intervention and 46 to control. Births and neonatal deaths were assessed in a baseline survey in 2005, monitored during the trial in 2008-2011 and followed up by a survey in 2014. Time series analyses were performed on monthly neonatal mortality data. Results There were 30187 live births and 480 neonatal deaths. The intervention reduced the neonatal mortality from 19.1 to 11.6 per 1000 live births. The reduction was sustained 3 years after the trial. The control areas reached a similar level at the time of follow-up. Time series decomposition analysis revealed a downward trend in the intervention areas during the trial that was not found in the control areas. Neonatal mortality peaked in the hot and wet summers.

Conclusions A community engagement intervention resulted in a lower neonatal mortality rate that was sustained but not further reduced after the end of the trial. When decomposing time series of neonatal mortality, a clear downward trend was demonstrated in intervention but not in control areas.

Trial registration number ISRCTN44599712, Postresults.

\section{INTRODUCTION}

Annually, 2.8 million neonates die worldwide ${ }^{1}$ despite existing knowledge on how to prevent a significant proportion of these deaths. ${ }^{2}$ Lack of knowledge how evidence-based practices should be implemented contributes to this dilemma. ${ }^{3}$ This problem calls for social or health systems interventions, for example, through the facilitation of local community groups that follow a problem-solving cycle. ${ }^{4}$ Meta-analyses of trials with women's group interventions show significantly reduced neonatal mortality. ${ }^{5}$ Hence, the WHO is currently recommending community engagement through facilitated participatory learning and action cycles with women's groups for maternal and newborn health. A further development of such strategies may be to engage people who already are involved in promoting health and welfare of women and children at the community level, for example, primary healthcare staff, village health workers and elected representatives of political and non-governmental organisations.

From 2008 to 2011, we conducted a cluster-randomised trial in a province in Vietnam, where local stakeholder groups supported by a facilitator ${ }^{7}$ worked with a perinatal problem-solving approach (NeoKIP trial, Neonatal Knowledge Into Practice, ISRCTN44599712). ${ }^{8}$ The facilitators mobilised and supported the groups in applying the PlanDo-Study-Act method, ${ }^{9}$ which included identifying and prioritising problems (Plan), undertaking planned actions (Do) and finally evaluating the effect and reconsidering the problems and actions (Study and Act). The intervention resulted in an increased attendance to antenatal care and reduced neonatal mortality (ORadj $0.51 ; 95 \% \mathrm{CI} 0.30$ to 0.89 ) after a latent period. ${ }^{10}$ The NeoKIP intervention was designed to enable an integration into the health system to increase the possibilities of having sustained effects. As NeoKIP was a complex social intervention, a latency period was expected. ${ }^{8}$ To detect the long-term effect of such intervention will require a data collection beyond the trial period Unfortunately, the evidence is frequently lacking regarding the sustainability of interventions aimed at increasing community engagement as trial data in most cases only cover the period before, during and at the end of a trial. ${ }^{112}$ Further, these trials are often implemented in settings with a seasonal variation $^{13-15}$ and a relative prominent secular trend in the mortality outcome. ${ }^{16}$

Time series analyses require large data sets with many measurements over time and can be appropriate approaches when analysing fluctuations of neonatal mortality, ${ }^{17}$ including seasonal variations 
of mortality rates. ${ }^{18}$ Time series information is built up by various factors, which might mask other differences in mortality over time, for example, the effect of an intervention. ${ }^{19}$ Therefore, when investigating the sustainability of an intervention, it is of interest to display the variation over a longer period including both the intervention and beyond. The aim of this study was to disentangle the secular trend, the seasonal variation and the effect of the community engagement intervention on neonatal mortality during and 3 years after the completion of the original trial.

\section{METHODS}

\section{Study area}

The NeoKIP trial was implemented in Quang Ninh province, located about $120 \mathrm{~km}$ east of Hanoi, bordering China in the north. The province has one million inhabitants and is currently undergoing a rapid economic development. Quang Ninh can be considered representative of Vietnam regarding geography, demography and administrative structure. Humid subtropical hot summers and dry winters characterise the climate in this part of Vietnam with the hottest period from May to September and the period with most rain from June to August. Antenatal and delivery care in Quang Ninh is provided at 187 commune health centres, 13 district hospitals and two provincial level hospitals.

Based on the data from the NeoKIP baseline survey, districts with a neonatal mortality rate $\geq 15$ deaths per 1000 live births were included in the trial. ${ }^{8}$ Hence, eight districts with 90 communes were selected as the study area with 44 communes randomly allocated as intervention communes and 46 as control communes. In the study area, there were approximately 350000 inhabitants and the overall neonatal mortality rate was 24 per 1000 live births. ${ }^{10}$

\section{Data collection}

Data on live births and neonatal deaths from the NeoKIP trial (July 2008-June 2011) were used in the current study. ${ }^{10}$ Also, a survey of live births and neonatal deaths ascertaining data for 12 months (July 2013-June 2014) was performed in 2014. Six data collectors were trained for 2 weeks. They attended monthly meetings at all commune health centres, all district hospitals and the two provincial level hospitals in the area to collect information on live births and neonatal deaths in the earlier NeoKIP study area. ${ }^{8}$ Further, the data collectors met all village health workers in the communes to collect data on live births and neonatal deaths in their villages. Triangulation was systematically performed of live births and neonatal deaths from all included sources (records and reports from the district, provincial and regional hospitals, commune health centres and village health workers) to ascertain that all data were registered and secure that no duplication of information occurred. A live birth was defined as 'birth of a fetus with any sign of viability', and a neonatal death was defined as 'a death of a live birth during the first 28 days of life'.

\section{Analysis}

\section{Mixed models}

The effect of the intervention (intervention communes vs control communes) on neonatal mortality was analysed using generalised linear mixed models in the R package 'Ime4'. ${ }^{20}{ }^{21}$ In these models, the intervention was included as a fixed factor nested within the random factor commune. The results were presented as OR with 95\% CI. Analyses were performed for the entire trial period of 3 years, for each year within the trial period separately and for the follow-up period.

\section{Time series analysis}

Classical decomposition of two time series (intervention and control) using moving averages was performed in R, assuming additive seasonal components. The neonatal mortality rate in the two time series was also analysed using the non-parametric Mann-Kendall test for monotonic trend in the $\mathrm{R}$ package 'Kendall'22 for the whole study period and after splitting the time series into trial period and follow-up period. Finally, time series analysis was performed using exponential smoothing state space models; ETS (Error, Trend, Seasonal) ${ }^{23}$ available in the $\mathrm{R}^{24}$ package 'forecast'. ${ }^{23}{ }^{25}$ ETS models were fitted to the two time series of monthly neonatal mortality rate data for intervention and control areas, respectively. Models with different error (additive vs multiplicative), trend (none vs additive) and seasonal components (none vs additive) for each time series, respectively, were compared using log-likelihood tests for the presence of trend and seasonality in the data.

\section{RESULTS}

All intervention and control clusters were included in the analysis during the trial period as well as in the follow-up. During the NeoKIP trial (years 1 to 3), there were 22377 live births and 389 neonatal deaths, whereas the 1 year NeoKIP follow-up period (year 6) included 7810 live births and 91 neonatal deaths (figure 1 and table 1).

As reported earlier, ethnicity, economic situation, education and utilisation of health services were similar among delivering women in the randomised intervention and control communes. ${ }^{10}$ The level of neonatal mortality rate was similar in intervention and control areas at the time of the baseline survey (table 1).

The 44 intervention communes had a downward trend in neonatal mortality rate and during the final year of the NeoKIP trial, the neonatal mortality rate was 11.6 per 1000 live births in the intervention communes and 21.1 per 1000 live births in the control communes. ${ }^{10}$ During the follow-up period, 6 years after the start of the trial, the level of neonatal mortality in the intervention communes was 11.1 - similar to the level in the final year of the trial. In the control communes, the corresponding level of neonatal mortality was 12.3 per 1000 live births, that is, not different from the intervention communes (table 1). The national neonatal mortality rates according to Unicef, WHO, UN Population Division and the World Bank ${ }^{26}$ were relatively stable 2005-2014, maybe with a decrease the last few years (table 1). The mortality levels in the study area in the Quang Ninh province were higher than the national average in 2005, ending at a similar level in 2014.

Figure 2 shows time series decomposition of the two time series on neonatal mortality rate in intervention and control areas. The components trend, season and random error are displayed. There was a downward trend during the trial period in the intervention communes. Mann-Kendall test provided evidence that there was a monotonic downward trend across the whole time series for the intervention area ( $\mathrm{tau}=-0.291, \mathrm{p}=0.004)$. This trend was also existing when including the trial period only (tau $=-0.299, \mathrm{p}=0.011$ ), but not when analysing the follow-up 6 years after the start of trial separately $(\mathrm{tau}=0.290, \mathrm{p}=0.216)$. The neonatal mortality rate in the control area did not show any monotonic trend (figure 2). Thus, no Mann-Kendall test could be performed for the whole time series. Neither was there any trend in the trial period nor the follow-up in the control 


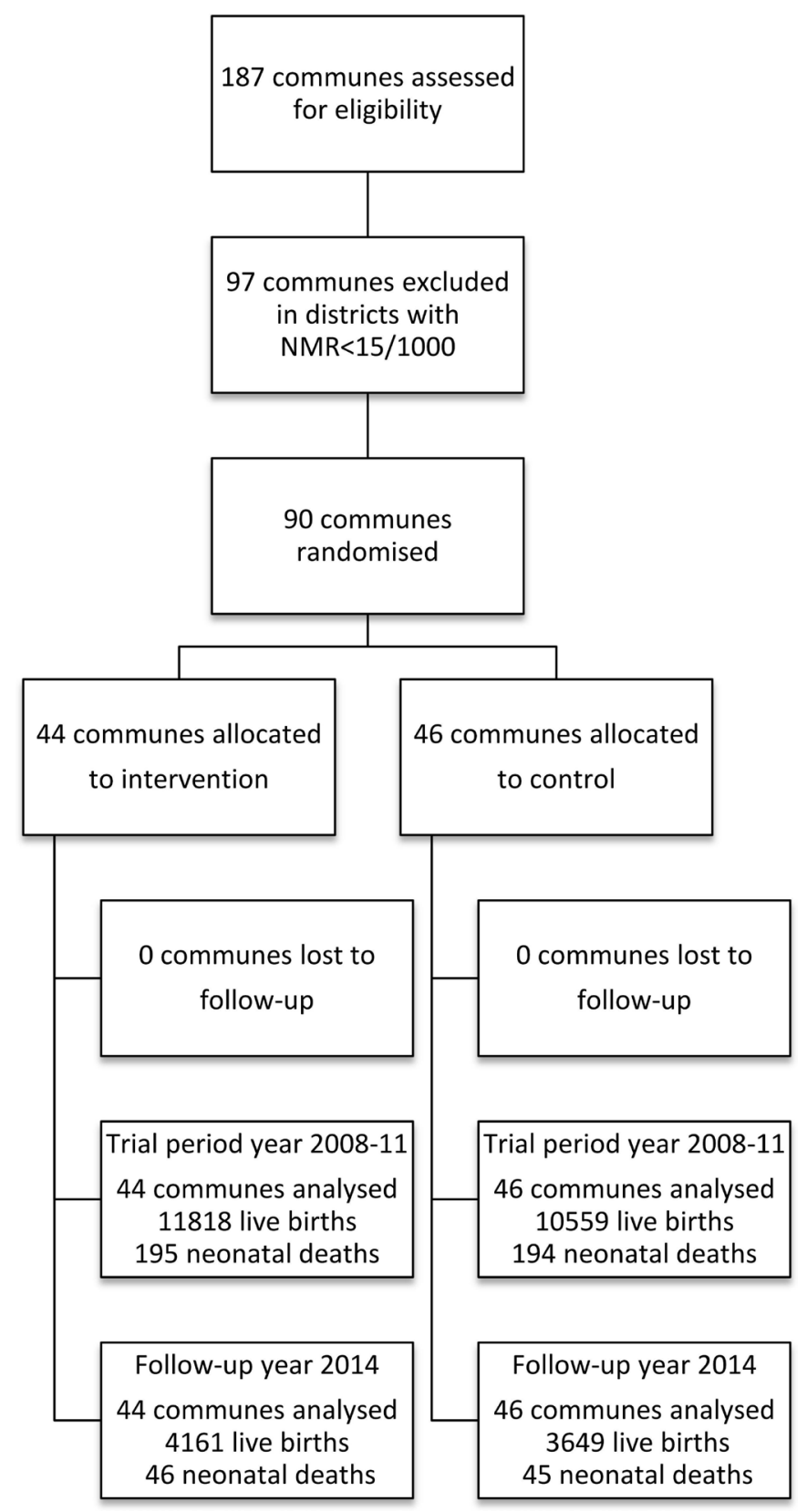

Figure 1 Study flow including trial and follow-up. NMR, neonatal mortality rates.

communes $(\mathrm{tau}=0.183, \mathrm{p}=0.120$ and tau $=-0.091, \mathrm{p}=0.731$, respectively).

Figure 2 geographically displays a seasonal pattern in neonatal mortality rates in both intervention and control areas. For the time series in the intervention area, an ETS model with additive random error terms, additive trend and additive seasonal component indeed was better than an ETS model with neither trend nor seasonality $(p=0.005)$. However, the $p$ value was higher when comparing the ETS model with additive error terms, additive trend and additive seasonal component with an ETS model with seasonality but no trend $(p=0.117)$. For the time series in the control communes, there was no statistical evidence found when using different models. Comparing an ETS model with multiplicative error terms and additive seasonality and trend with a model with multiplicative error terms, no trend and no seasonal component showed no statistically significant improvement

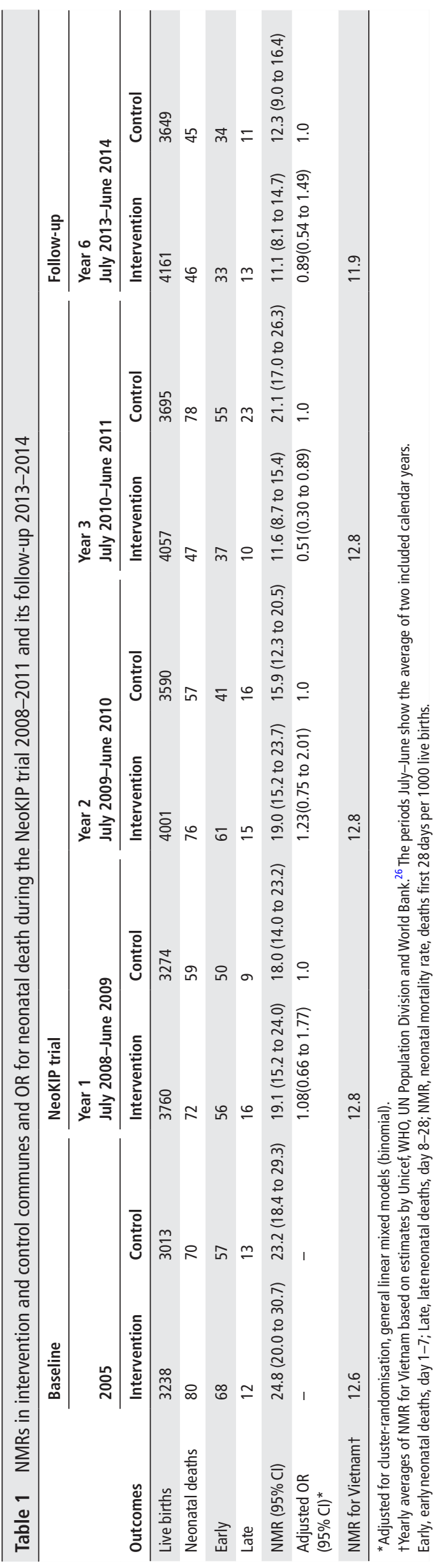

Eriksson L, et al. J Epidemiol Community Health 2018;72:776-782. doi:10.1136/jech-2017-209252 


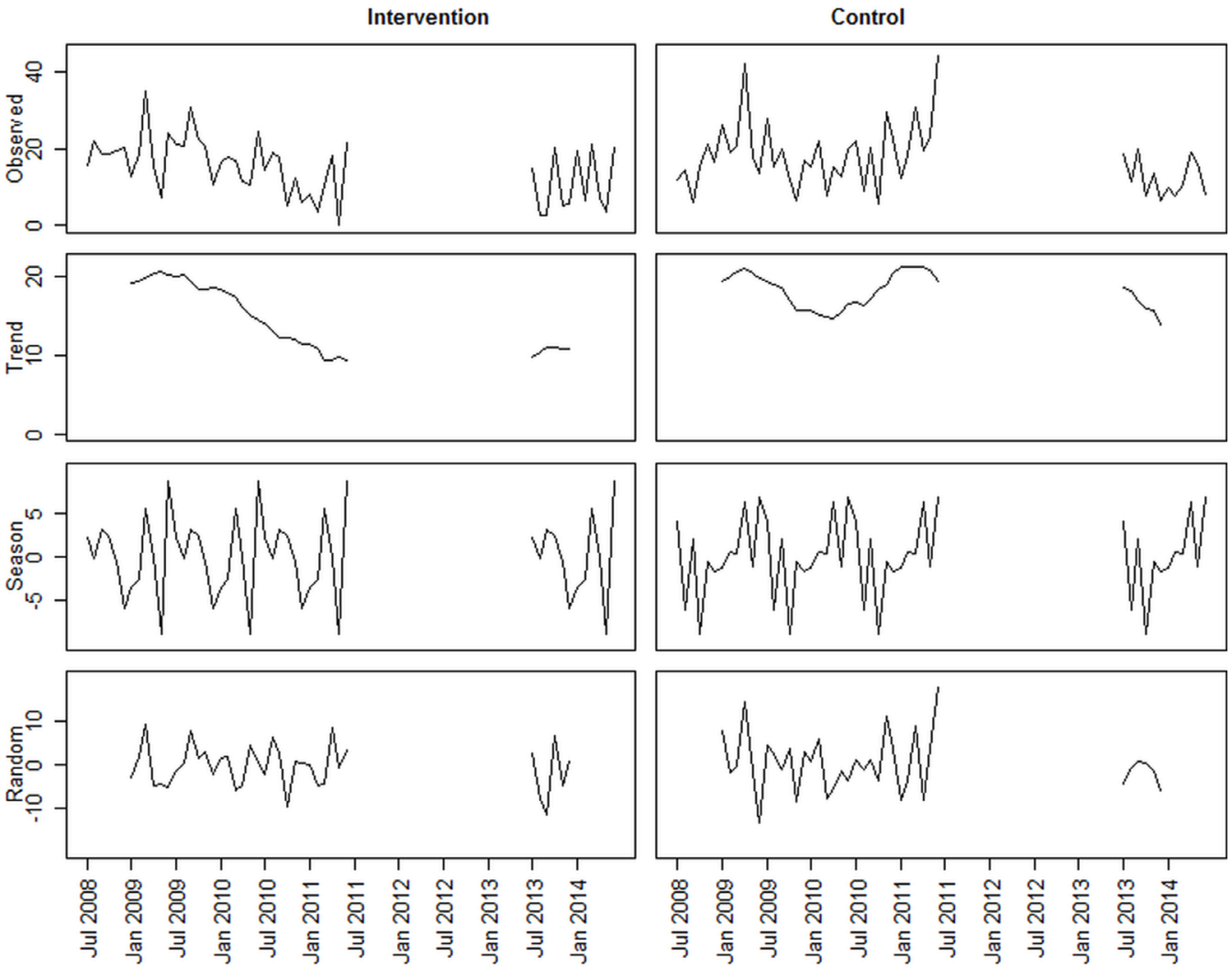

Figure 2 Time series decomposition of neonatal mortality rate in intervention and control areas during the NeoKIP trial (2008-2011) and its followup (2013-2014).

$(\mathrm{p}=0.175)$. Further, when comparing an ETS model having multiplicative error terms, additive seasonality and no trend with a model having multiplicative error terms, no seasonality or trend, the $p$ value was somewhat smaller $(p=0.115)$.

There were minor differences in seasonal variation of neonatal mortality rates between intervention and control communes (figure 2). More importantly, there was an overall pattern with the highest death rate in June that is characterised by heavy rainfall and heat and the lowest in the winter from November to February (figure 3).

\section{DISCUSSION}

A randomised facilitated intervention in a Vietnamese province with local maternal and newborn stakeholder groups composed of primary care staff and local politicians, who used a problem-solving approach for 3 years, significantly reduced neonatal mortality after a latent period. ${ }^{10}$ This follow-up 3 years after the end of the trial showed no further reduction of neonatal mortality from the level of 11 per 1000 live births in the intervention areas. The control areas that had almost the double

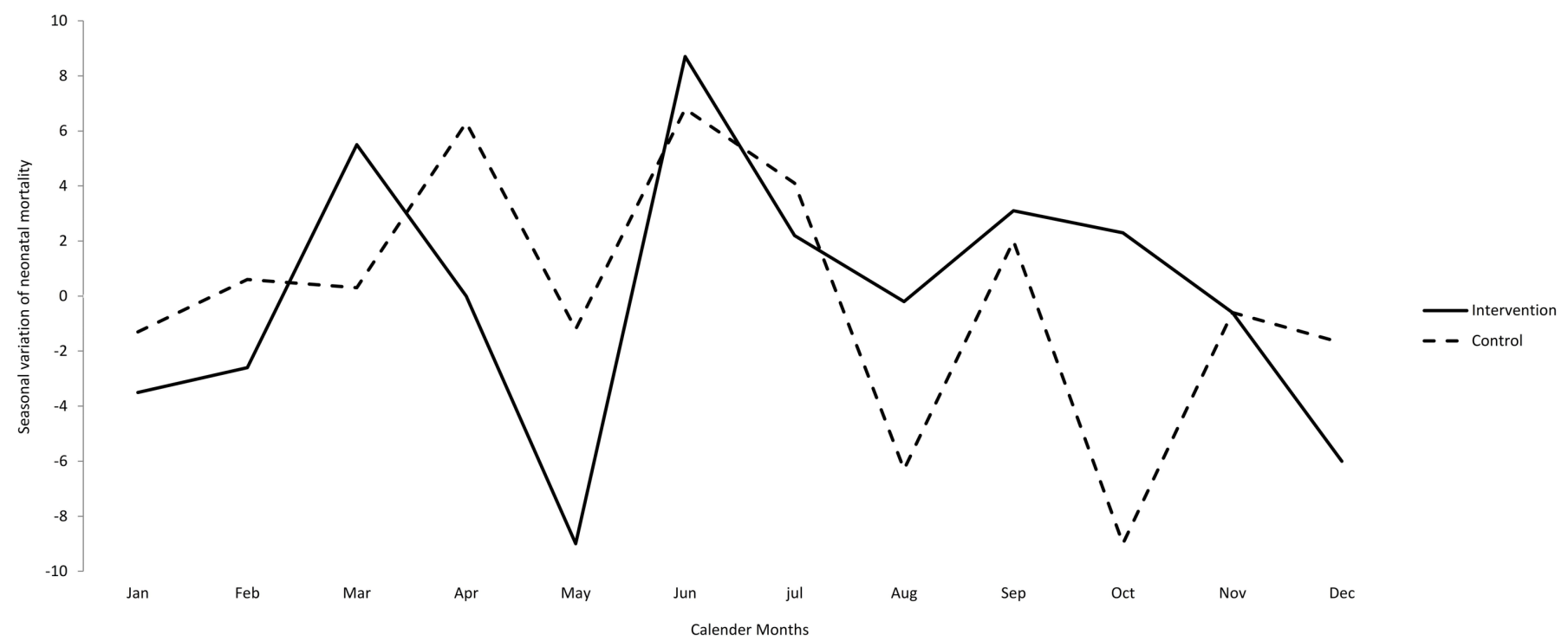

Figure 3 Seasonal component of time series decomposition in intervention and control communes based on data from four complete years. 
neonatal mortality at the end of the trial had reached a similar level as the intervention area at the time of the follow-up. Time series analysis revealed a downward trend in the intervention areas during the trial that was not found in the control areas. There was also a seasonal mortality pattern across the observed years with peak mortality in the wet and hot June and lower levels in the winter.

\section{Methodological considerations}

Baseline characteristics of the mothers were similar in intervention and control communes ${ }^{10}$ and the neonatal mortality rate did not differ between the two trial arms in the 2005 baseline survey (table 1). The data collection methodology had previously been applied in the NeoKIP trial and found to provide valid information. ${ }^{1027}$ The outcome data collection system was also separated from the facilitated intervention activities during the trial. NeoKIP was a complex social intervention. It was context-specific and continuously subjected to negotiation and interpretation among the involved local stakeholders. In the protocol of this trial, a latent period was considered, but the duration of this latency was not prespecified. ${ }^{8}$ There was an interval with no data collection from the completion of the trial in July 2011June 2013. Covering this gap by an extended recall period in the follow-up survey in 2014 should have increased the risk of recall bias. In the time series analysis, this interval without data was disregarded. The development of neonatal mortality in the intervention and control communes during the interim period is unknown. We also performed separate analyses, that is, including the trial period of 3 years and follow-up of 1 year, respectively. The disadvantage with the latter analyses was the short period, especially the 1-year follow-up period. Therefore, a decision was made to merge the first three and the final follow-up year for a longer time series analysis.

\section{Secular trend in neonatal mortality}

The societal reforms in Vietnam in the mid-1980s were immediately followed by improved postneonatal and child survival, as shown in the analyses of data from a demographic surveillance site in the Red River Delta area. ${ }^{28}$ This reduction in mortality was not accompanied by improved neonatal survival that instead persisted at the same level as in the early 1970s up to the millennium shift. The national estimates of neonatal mortality 20052014 were relatively constant, maybe with some reduction during the last few years (table 1). ${ }^{26}$ There was no downward trend in neonatal mortality in the control communes, neither during the trial period alone nor when including the follow-up period (figure 2, table 1). Still, the neonatal mortality in the control communes at time of the follow-up had reached the level of national averages. However, if data for the interim period had been available, maybe the result of the trend analysis for those years had been different.

\section{Seasonal variation in neonatal mortality}

The seasonal variation in neonatal mortality in intervention as well as control arms had a pattern with peak mortality in the hot and rainy summer and lower mortality in the dry winter (figure 3). This finding is in line with other studies from Asia. ${ }^{13-15}$ The hot and wet season increases the risk of infectious diseases mortality. ${ }^{18}$ The rainy period also implies that attendance to antenatal and delivery care becomes complicated due to transport difficulties. The distance decay in healthcare utilisation increases, and the risk of neonatal death, especially for the preterm babies, increases. ${ }^{29}$ Our analysis of the causes of neonatal death during the NeoKIP trial period showed that 4 out of 10 deaths had been born preterm, one-third had an intrapartum cause of death or birth asphyxia and 13\% were caused by infections. ${ }^{30}$ A recent systematic review suggests that seasonality gradually become less critical for societies in transition. ${ }^{18}$ This fact does not preclude that climate change and extreme weather in the future will increase seasonal variation in newborn mortality. $^{31}$

\section{Effects of the intervention}

The intervention communes depicted a monotonic downward trend in neonatal mortality that was not seen in the control communes (figure 2). The latency period that was evident in the observed data was not visible after time trend decomposition. The NeoKIP intervention was integrated into the existing health system and built on local community engagement for maternal and newborn health. This integration could possibly increase the likelihood that the effects of the intervention were sustained, that is, that further reduction in neonatal mortality took place exceeding that of the control areas. However, the trial did not include any agreement with the regional health authorities or local stakeholders to institutionalise the monthly group activities.

At the end of the NeoKIP trial, there was a significantly lower neonatal mortality rate in the intervention communes compared with the control communes: 11.6 and 21.1 per 1000 live births, respectively. This difference was not present 6 years after start of the trial as the mortality levels were similar in intervention and control communes (11.1 and 12.3, respectively). These findings imply that the intervention communes had remained at a low level despite no further intervention activities and that the control communes had closed the gap. To see a reduction in control areas over time was not surprising considering the downward trend in the national estimates of neonatal mortality rates. ${ }^{26}$ A recent qualitative study conducted during the NeoKIP follow-up showed that maternal and neonatal care still received high priority by healthcare workers in the intervention communes and leaders at different levels of the health system 3 years after completion of the trial. ${ }^{32}$ The local engagement for women's and newborn's health seen during and after the completion of the NeoKIP trial could have contributed to the lowering of neonatal mortality level in the intervention communes with a diffusion to control areas where reduced neonatal mortality rates were also observed.

A recent meta-analysis covering seven trials and almost 120000 births concluded that the use of facilitated women's groups practicing Plan-Do-Study-Act method on the community level is a cost-effective strategy to improve maternal and neonatal survival in low-resource settings substantially. ${ }^{5}$ Based on this evidence, community engagement through facilitated women's groups is now recommended by the WHO. ${ }^{6}$ In the NeoKIP trial, a complex social intervention was also evaluated, but the intention was instead to ensure health system integration by the use of stakeholders who have responsibility for, and are working with health and well-being in society. The use of time series analysis in the current study supports the strengths of this intervention by revealing a downward trend in neonatal mortality in the intervention areas during and beyond the trial period.

An increasing majority of births in this province and overall in Vietnam take place at health facilities, mainly hospitals. ${ }^{33}$ To achieve further reduction of preterm and birth asphyxia deaths, efforts to improve the quality of services provided at hospitals may be needed. ${ }^{10}$ It has been stated that for reduction of neonatal mortality below 15 per 1000 live births, a good quality 


\section{What is already known on this subject}

- Knowledge exists on how to prevent a large proportion of the annual neonatal deaths that occur globally. However, there is a limited insight on how this knowledge should be implemented and sustained.

\section{What this study adds}

- A randomised facilitated community engagement intervention lowered the level of neonatal mortality from 19.1 to 11.6 per 1000 live births (2008-2011); there was no further reduction 3 years after the end of the trial (2014).

- A time series analysis (2008-2014) revealed a downward trend in neonatal mortality in intervention communes but not in control communes.

- There was a marked seasonal variation with a peak in neonatal mortality during the wet and hot summer, a season when access to services in remote areas is difficult and infection rates are high.

of services provided at health facilities is a prerequisite. ${ }^{34}$ In recent years, the Vietnamese Ministry of Health has emphasised the perinatal period and provision of good quality maternal, newborn and child health services. ${ }^{35} 36$ This may be reflected in the country's achievements regarding the fourth Millennium Development Goal and maybe also in the recent national estimates of the neonatal mortality rate.

\section{CONCLUSION}

A randomised facilitated community engagement intervention significantly reduced neonatal mortality. A time trend decomposition analysis showed a monotonous decrease in mortality in the intervention areas. A follow-up 3 years after the end of the trial revealed a sustained low level of neonatal mortality but no further reduction in the intervention areas, while the control areas had reduced the gap in newborn survival. This reduction in mortality in control areas corresponded to national efforts for improved perinatal health and some reduction in the national neonatal mortality rate estimates. The death rates had a marked seasonal variation with a peak in mortality during the wet and hot summer, a season with more infections and difficulties to get access to services in remote areas.

\footnotetext{
Author affiliations

${ }^{1}$ Department of Public Health and Caring Sciences, Uppsala University, Uppsala, Sweden

${ }^{2}$ International Maternal and Child Health (IMCH), Department of Women's and Children's Health, Uppsala University, Uppsala, Sweden

${ }^{3}$ Research Institute for Child Health, Hanoi, Vietnam

${ }^{4}$ Hanoi University of Public Health, Hanoi, Vietnam

${ }^{5}$ Institute for Global Health, University College London, London, UK

${ }^{6}$ School of Education, Health and Social Studies, Dalarna University, Falun, Sweden

${ }^{7}$ Department of Neurobiology, Care Sciences and Society, Division of Nursing,

Karolinska Institutet, Stockholm, Sweden

${ }^{8}$ Department of Health and Care Sciences, The Sahlgrenska Academy, University of Gothenburg, Gothenburg, Sweden

${ }^{9}$ Department of Medical Services Administration, Ministry of Health, Nursing office, Hanoi, Vietnam

${ }^{10}$ Vietnam-Sweden Uong Bi General Hospital, Uong Bi, Vietnam

${ }^{11}$ National Institute of Nutrition (NIN), Ministry of Health, Hanoi, Vietnam

${ }^{12}$ London School of Hygiene \& Tropical Medicine, London, UK
}

Acknowledgements We are grateful to the participating healthcare staff in Quang Ninh province, Vietnam, for their support to data collection.

Contributors Conception and design: LE, NTN, DTPH, DMD, AB, LW, MM, UE, L-ÅP, KES. Acquisition of data: LE, NTN, DTPH, DMD, AB, LW, MM, TQH, NTT, TTD, PTLL. Analysis and interpretation of data: LE, NTN, L-ÅP, KES. Wrote the first draft of the manuscript: LE. Contributed to the writing of the manuscript: LE, NTN, DTPH, DMD, $A B, L W, M M, U E, T Q H, N T T, T T D, P T L L, L-A ̊ P, K E S$. Agree with final version of the manuscript: LE, NTN, DTPH, DMD, AB, LW, MM, UE, TQH, NTT, TTD, PTLL, L-ÅP, KES. Agree to be accountable for all aspects of the work: LE, NTN, DTPH, DMD, AB, LW, MM, UE, TQH, NTT, TTD, PTLL, L-ÅP, KES.

Funding This work was supported by the Swedish Research Council (348-20136546) and Uppsala University (2015/1148).

Competing interests None declared.

Patient consent Not required.

Ethics approval The Provincial Department of Science and Technology of the Quang Ninh province, Vietnam (ref. 1658/QD-UBND) and the Research Ethics Committee at Uppsala University, Sweden (ref. 2014:205).

Provenance and peer review Not commissioned; externally peer reviewed.

Open access This is an open access article distributed in accordance with the Creative Commons Attribution Non Commercial (CC BY-NC 4.0) license, which permits others to distribute, remix, adapt, build upon this work non-commercially, and license their derivative works on different terms, provided the original work is properly cited and the use is non-commercial. See: http://creativecommons.org/ licenses/by-nc/4.0/

(C) Article author(s) (or their employer(s) unless otherwise stated in the text of the article) 2018. All rights reserved. No commercial use is permitted unless otherwise expressly granted.

\section{REFERENCES}

1 Unicef, World Helath Organization, The World Bank, et al. Levels and trends in child mortality. report 2014. estimates developed by the UN inter-agency group for child mortality estimation, 2014

2 Darmstadt GL, Bhutta ZA, Cousens S, et al. Evidence-based, cost-effective interventions: how many newborn babies can we save? Lancet 2005;365:977-88.

3 Cavagnero E, Daelmans B, Gupta N, et al. Assessment of the health system and policy environment as a critical complement to tracking intervention coverage for maternal, newborn, and child health. Lancet 2008;371:1284-93.

4 Osrin D, Prost A. Perinatal interventions and survival in resource-poor settings: which work, which don't, which have the jury out? Arch Dis Child 2010;95:1039-46.

5 Prost A, Colbourn T, Seward N, et al. Women's groups practising participatory learning and action to improve maternal and newborn health in low-resource settings: a systematic review and meta-analysis. Lancet 2013;381:1736-46.

6 World Helath Organization. WHO recommendation on community mobilization through facilitated participatory learning and action cycles with women's groups for maternal and newborn health. Geneva: World Helath Organization, 2014.

7 Harvey G, Loftus-Hills A, Rycroft-Malone J, et al. Getting evidence into practice: the role and function of facilitation. J Adv Nurs 2002;37:577-88.

8 Wallin L, Målqvist M, Nga NT, et al. Implementing knowledge into practice for improved neonatal survival; a cluster-randomised, community-based trial in quang ninh province, Vietnam. BMC Health Serv Res 2011;11:239.

9 Langley G, Moen R, Nolan K, et al. The Improvement Guide. a practical approach to enhancing organizational performance. Chichester: Jossey Bass Wiley, 2009.

10 Persson LÅ, Nga NT, Målqvist M, et al. Effect of facilitation of local maternal-andnewborn stakeholder groups on neonatal mortality: cluster-randomized controlled trial. PLoS Med 2013;10:e1001445.

11 Haines A, Kuruvilla S, Borchert M. Bridging the implementation gap between knowledge and action for health. Bull World Health Organ 2004;82:724-31.

12 Chambers DA, Glasgow RE, Stange KC. The dynamic sustainability framework: addressing the paradox of sustainment amid ongoing change. Implement Sci 2013;8:117.

13 Burkart K, Khan MH, Krämer A, et al. Seasonal variations of all-cause and causespecific mortality by age, gender, and socioeconomic condition in urban and rural areas of Bangladesh. Int J Equity Health 2011;10:32.

14 Hughes MM, Katz J, Mullany LC, et al. Seasonality of birth outcomes in rural Sarlahi District, Nepal: a population-based prospective cohort. BMC Pregnancy Childbirth 2014;14:310.

15 Mannan I, Choi Y, Coutinho AJ, et al. Vulnerability of newborns to environmental factors: findings from community based surveillance data in Bangladesh. Int J Environ Res Public Health 2011:8:3437-52

16 Oestergaard MZ, Inoue M, Yoshida S, et al. Neonatal mortality levels for 193 countries in 2009 with trends since 1990: a systematic analysis of progress, projections, and priorities. PLoS Med 2011;8:e1001080. 
17 Shumway RH. Time Series Analysis and Its Applications. With R examples. Springer 2006.

18 Burkart K, Khan MM, Schneider A, et al. The effects of season and meteorology on human mortality in tropical climates: a systematic review. Trans $R$ Soc Trop Med Hyg 2014; 108:393-401.

19 Coghlan A. A little book of $r$ for time series. release 0.2: Cambridge, 2015.

20 Bates $\mathrm{AD}$, Maechler M, Bolker B, et al. Ime4: linear mixed-effects models using eigen and S4. R package version 1.1-7, 2014

21 Bates AD, Maechler M, Bolker BM, et al; Ime4: linear mixed-effects models using Eigen and S4, 2014.

22 McLeod Al. Kendall: kendall rank correlation and mann-kendall trend test. R package version 2.2, 2011.

23 Hyndman RJ, Koehler AB, Ord JK, et al. Forecasting with exponential smoothing: The State Space Approach: Springer, 2008.

24 Core Team R. R: a language and environment for statistical computing. Vienna, Austria: R Foundation for Statistical Computing, 2014.

25 Hyndman RJ. Forecast: forecasting functions for time series an linear models. $R$ package version 6.1, 2015.

26 Unicef WHO, Division UP, et al. Child mortality estimates Vietnam, 2015.

27 Målqvist M, Eriksson L, Nguyen TN, et al. Unreported births and deaths, a severe obstacle for improved neonatal survival in low-income countries; a population based study. BMC Int Health Hum Rights 2008;8:4.
28 Hoa DP, Nga NT, Målqvist M, et al. Persistent neonatal mortality despite improved under-five survival: a retrospective cohort study in northern Vietnam. Acta Paediatr 2008;97:166-70.

29 Målqvist M, Sohel N, Do TT, et al. Distance decay in delivery care utilisation associated with neonatal mortality. A case referent study in northern Vietnam. BMC Public Health 2010;10:762.

30 Nga NT, Hoa DT, Målqvist M, et al. Causes of neonatal death: results from NeoKIP community-based trial in quang ninh province, Vietnam. Acta Paediatr 2012;101:368-73.

31 Ahdoot S, Pacheco SE. Council on environmental h. global climate change and children's health. Pediatrics 2015;136:84.

32 Eriksson L, Bergström A, Hoa DTP, et al. Sustainability of knowledge implementation in a low- and middle- income context: Experiences from a facilitation project in Vietnam targeting maternal and neonatal health. PLoS One 2017;12:e0182626.

33 Nga NT, Målqvist M, Eriksson L, et al. Perinatal services and outcomes in quang ninh province, Vietnam. Acta Paediatr 2010;99:1478-83.

34 Knippenberg R, Lawn JE, Darmstadt GL, et al. Systematic scaling up of neonatal care in countries. Lancet 2005;365:1087-98.

35 Ministry of Health Vietnam. National standards and guidelines for reproductive health care services. Hanoi: Ministry of Health, 2002.

36 Ministry of Health Vietnam. Ministry of health directive on newborn health: 04/2003/ CT-BYT. Hanoi: Ministry of Health, 2003. 